\title{
MODEL PENGUKURAN KINERJA CUSTOMER RELATIONSHIP MANAGEMENT DALAM INDUSTRI PERBANKAN
}

\author{
Freddy Simbolon \\ Management Department, School of Business Management, BINUS University \\ Jln. K.H. Syahdan No.9, Palmerah, Jakarta Barat 11480 \\ freddysimbolon@binus.ac.id
}

\begin{abstract}
High competition in the banking industry requires the banking industry to properly manage relationships with customers, as it is known as Customer Relationship Management (CRM). CRM applications will become effective when supported by information technology. Investment in information technology is not a small investment, because the higher the information technology, the greater the value of the investment. This study aims to obtain a model of CRM performance measurement in the banking industry efficiently and effective. The method in this study uses descriptive analytical method, while the results obtained in this study is a CRM Scorecard. CRM Scorecard is one of the approach models that correctly measure the performance of CRM, which is based on information technology. Through CRM Scorecard approach, information technology investment in CRM is no longer seen as a cost center, but seen to be a profit center, because the company can manage customers efficiently and effectively in order to enhance shareholder value in the future.
\end{abstract}

Keywords: CRM, CRM scorecard, information technology, banking industry

\begin{abstract}
ABSTRAK
Persaingan yang tinggi dalam industri perbankan menuntut industri perbankan untuk mengelola dengan baik hubungan baik dengan pelanggan, seperti yang dikenal sebagai Customer Relationship Management (CRM). Aplikasi CRM akan menjadi efektif bila didukung dengan teknologi informasi. Investasi teknologi informasi bukanlah hal yang kecil, karena semakin tinggi teknologi informasi semakin tinggi pula nilai investasinya. Penelitian ini bertujuan untuk mendapatkan model pengukuran kinerja CRM dalam industri perbankan secara efisien dan efektif. Metode dalam penelitian ini menggunakan metode deskriptif analitis, adapun hasil yang didapatkan dalam penelitian ini adalah CRM Scorecard. CRM Scorecard adalah salah satu model pendekatan yang mengukur dengan tepat kinerja CRM, yang berbasiskan teknologi informasi. Melalui pendekatan CRM Scorecard, investasi teknologi informasi dalam CRM tidak lagi dipandang sebagai cost center, tapi dipandang menjadi profit center, karena perusahan dapat mengelola pelanggan secara efisien dan efektif guna meningkatkan nilai perusahaan di masa mendatang.
\end{abstract}

Kata kunci: CRM, CRM scorecard, teknologi informasi, industri perbankan 


\section{PENDAHULUAN}

Mengutip hasil penelitian Winer (2001) yang menyatakan bahwa biaya menjaga pelanggan lama ternyata lebih murah dibandingkan dengan biaya mendapatkan pelanggan baru. Selain itu pula biaya untuk membina pelanggan lama lebih murah untuk memberikan hasil yang menjanjikan. Hasil ini memberikan indikasi bahwa penghematan bisa dilakukan bila perusahaan lebih peduli menjaga hubungan baik kepada pelanggan dan bahkan lebih dari itu, bahwa membina pelanggan lama lebih menjanjikan di masa depan.

Menurut hasil penelitian Gupta, et al. (2002), jika perusahaan berhasil mendorong retensi (tingkat belanja ulang) 1\% saja dari jumlah pelanggan lama, maka perusahaan tersebut akan mengalami peningkatan keuntungan sebesar 5\%. Hasil ini pun telah memberikan gambaran bahwa betapa pentingnya perusahaan untuk mengelola pelanggan lama untuk mendongkrak penjualan perusahaan.

Di dalam pemasaran, mengelola atau menjaga hubungan baik dengan pelanggan dilakukan dalam ruang lingkup Customer Relationship Management (CRM). Ilmu ini adalah tentang bagaimana mengelola hubungan dengan baik agar hubungan jangka panjang tercipta atau loyalitas pelanggan yang terukur dan memberikan manfaat bagi perusahaan untuk jangka panjang. Hal ini seperti yang diungkapkan oleh O’Brien (2002: 130) bahwa CRM memungkinkan perusahaan mengidentifikasi dan membidik pelanggan terbaiknya, yaitu mereka yang menguntungkan perusahaan, sehingga mereka dapat dipertahankan menjadi pelanggan yang setia untuk jangka panjang. Mereka diharapkan akan memberikan keuntungan yang lebih besar bagi perusahaan.

Salah satu industri yang sarat dengan kepentingan menjaga hubungan baik kepada pelanggan dan membangun keandalan teknologi informasi adalah industri perbankan. Kandungan Teknologi Informasi (TI) dalam industri perbankan semakin hari semakin besar dan kompleks, atau dengan kata lain adalah mustahil apabila saat ini menjalankan bisnis perbankan tanpa memanfaatkan dukungan TI dalam operasionalnya. Bank menganggap pemanfaatan teknologi mampu memberikan keefektifan dan efisiensi dari aspek keamanan data, kecepatan pelayanan serta kemampuan bersaing. Oleh karena itu, bank dengan teknologi yang unggul akan menjadi pilihan nasabah, karena tidak dipungkiri bahwa teknologi dapat mendukung layanan yang cepat dan tepat sehingga pada akhirnya mampu memenuhi kepuasan nasabah (Kim, et al., 2007).

Salah satu perusahaan perbankan yang telah sukses menjalankan CRM adalah Hong Kong's Mevas Bank. Ketika pertama kali menerapkan CRM, Bank ini tidak mempunyai sebuah cabang pun. Pelanggan hanya dapat melakukan transaksi secara on-line melalui website. Staff Bank berada di tempat untuk menjawab pertanyaan melalui website dan melayani permintaan investasi secara on line. Web sebagai media bagi nasabah untuk melakukan berbagai transaksi (personal banking tools), sedangkan Mevas Bank hanya sebagai tempat untuk keperluan bertatap muka. Pendekatan media ini telah mampu menurunkan biaya operasional dan meningkatkan profit. Saat itu Mevas Bank dapat melayani 10,000 nasabah dengan jumlah 20 staff service representatives (Greenberg, 2001:1). Sedangkan di Indonesia, perbankan yang telah sukses menerapakan CRM yang berbasiskan teknologi informasi adalah BCA melalui www.klikbca.com, media ini telah memudahkan nasabah untuk bertransaksi perbankan tanpa harus ke kantor cabang. Saat ini sudah sebagian besar perbankan telah banyak mengaplikasikan CRM yang berbasiskan teknologi informasi, seperti Bank Mandiri, BNI, BRI, Niaga, dan lainnya.

Perbankan sebagai salah satu industri yang mengedepankan pelayanan kepada pelanggan dan sarat akan teknologi informasi, konsep CRM menjadi penting untuk dijalankan agar tingkat kepercayaan nasabah terhadap layanan perbankan semakin meningkat. Namun demikian, teknologi 
informasi dalam industri perbankan membutuhkan nilai investasi yang sangat besar. Semakin tinggi tingkat pelayanan nasabah yang diberikan akan menuntut investasi teknologi informasi yang besar pula.

Untuk itu, permasalahan yang timbul adalah memberikan dukungan keandalan teknologi informasi untuk memenuhi tuntutan pelayanan yang tinggi kepada pelanggan, kondisi ini berdampak pula kepada tingginya nilai investasi teknologi informasi. Implementasi CRM yang berbasiskan teknologi informasi akan menjadi efektif apabila kinerja CRM juga diukur, baik itu kinerja pada sisi operasional perusahaan dan kinerja pada sisi loyalitas pelanggan. Artinya, perusahaan harus mengukur nilai investasi teknologi informasi yang sudah dilakukan harus membawa pengaruh pada tingginya loyalitas pelanggan dan nilai bagi perusahaan di masa depan.

Permasalahan yang harus dijawab dalam penelitian ini adalah bagaimana model pengukuran kinerja CRM yang berbasiskan teknologi informasi sehingga ketika diterapkan, CRM dapat memberikan manfaat yang besar bagi pelanggan dan perusahaan. Dengan demikian tujuan yang akan dicapai dalam penelitian ini adalah untuk mendapatkan model pengukuran kinerja CRM guna memaksimalkan manfaat penerapan CRM bagi perusahaan dan pelanggan.

\section{Pengertian CRM}

Konsep CRM merupakan sebuah konsep di mana perusahaan berfokus pada pelanggan (customer-centric). Konsep ini disebut strategi sebagai pengelolaan hubungan dengan pelanggan atau dikenal dengan istilah Customer Relationship Management (CRM). Konsep CRM sudah berkembang sejak beberapa tahun terakhir karena kompetisi dan tuntutan pelanggan yang meningkat pada pelayanan yang lebih baik dan perhatian yang lebih besar terhadap kebutuhan individual pelanggan. Gagasan utama CRM adalah membantu perusahaan dengan menggunakan teknologi, proses bisnis, dan sumber daya manusia untuk memperoleh informasi mengenai perilaku dan nilai dari pelanggan tersebut.

Selain itu, menurut O’Brien (2002:131) CRM memungkinkan realtime customization and personalization atas produk dan jasa berdasarkan keinginan, kebutuhan, kebiasaan pembelian dan siklus kehidupan pelanggan. CRM juga memantau data pelanggan setiap kali melakukan kontak dengan perusahaan. CRM memungkinkan perusahaan untuk menyediakan layanan dan dukungan yang konsisten dan prima terhadap semua kontak yang diinginkan pelanggan sehingga pelanggan memperoleh pengalaman yang menyenangkan. Semua keuntungan ini memberikan nilai bisnis yang strategis bagi perusahaan sekaligus perceived value bagi pelanggan.

Secara konsep, Customer Relationship Management (CRM), adalah strategi bisnis yang terdiri dari software dan layanan yang didesain untuk meningkatkan keuntungan (profit), pendapatan (revenue) dan kepuasan pelanggan (customer satisfaction). Meningkatkan keuntungan, pendapatan dan kepuasan pelanggan dengan cara membantu perusahaan dalam mengidentifikasi pelanggan, meningkatkan jumlah pelanggan dengan lebih cepat dan mempertahankan kesetiaan pelanggan.

Menurut Costanzo (2003:8), CRM merujuk pada software system yang membantu perusahaan memperoleh dan menyimpan data pelanggan serta melakukan hubungan dua arah. Tetapi saat ini CRM lebih menekankan pada perubahan kebijakan dan prosedur yang didesain untuk meningkatkan sales dan customer retention di berbagai lini perusahaan.

\section{CRM dan Teknologi Informasi}

Perlunya teknologi informasi di dalam konsep CRM seperti yang diungkapkan oleh O’Brien (2002:130), menurutnya CRM menggunakan teknologi informasi untuk menciptakan cross-functional enterprise system yang mengintegrasikan dan mengotomatisasi proses layanan pelanggan dalam 
bidang penjualan, pemasaran, dan layanan produk/jasa berkaitan dengan perusahaan. Sistem CRM juga menciptakan IT framework yang menghubungkan semua proses dengan bisnis operasional perusahaan. Selain itu sistem CRM juga meliputi sekumpulan modul software yang membantu aktivitas bisnis perusahaan, seperti proses kantor depan.

Pendapat lain dikemukakan oleh Cannon, Perreault \& McCarthy (2008: 379), bahwa aplikasi teknologi informasi digunakan pada database CRM bagi pelanggan perusahaan. Sebagai contoh, Forrester Reasearch melakukan riset pasar terhadap bermacam-macam industri dan kemudian menjual hasil riset pasarnya kepada publik. Pelanggan yang mengakses website Forrester dan menginginkan industri dan topik yang dipilih dapat mendaftar. Selanjutnya Forrester akan mengirimkan e-mail secara regular dengan data yang diperbarui seperti yang pelanggan inginkan.

Demikian pula yang dikemukakan oleh Whitaker (2005: 50) juga menegaskan bahwa penggunaan database CRM dalam bisnis akan membantu perusahaan untuk mengetahui alir seluruh aktivitas mulai panggilan telepon untuk order penjualan hingga permintaan layanan. Dengan adanya sentralisasi semua komunikasi yang terjadi dengan pelanggan pada suatu tempat akan meningkatkan efisiensi. Ketika ada konsistensi maka akan terbentuk kemampuan untuk mengukur dan mengelola sumber daya manusia dan semua proses yang terjadi.

Atas dasar pendekatan tersebut, dapat disimpulkan bahwa CRM adalah serangkaian pendekatan dan sistem yang berbasis teknologi informasi (IT-Based System) yang berguna untuk menjalin hubungan bisnis yang lebih erat dan terbuka. CRM menghubungkan komunikasi dua arah antara perusahaan dengan pelanggannya, baik sebagai stakeholder maupun shareholder.

\section{Mengukur Kinerja CRM}

Menurut Brewton (2009) pengukuran kinerja CRM didefinisikan sebagai sebuah sistem pengukuran yang sengaja menghubungkan tujuan jangka panjang strategi CRM, tujuan dan langkahlangkah tertentu, strategi jangka pendek serta ukuran dan tindakan-tindakan yang mengarah ke kinerja CRM. Selain itu pula, menurut Kim, et al.(2007) diungkapkan bahwa perusahaan yang menerapkan strategi CRM, mengetahui bahwa biaya dan keuntungan yang diperoleh dari inisiatif CRM adalah signifikan, dan mereka berusaha untuk menggapai pengaruh keuangan dan faktor-faktor ekonomi yang berkontribusi terhadap keuntungan nyata (tangible benefits) bagi perusahaan demikian juga dengan keuntungan tidak nyata (intangible benefits). Pengukuran kinerja CRM sangatlah penting untuk mengetahui apakah strategi yang dijalankan telah mencapai sasaran yang dituju sekaligus memberikan umpan balik bagi perusahaan untuk menyusun sasaran strategis di masa mendatang.

Berbagai kerangka pengukuran kinerja CRM telah banyak dikemukakan oleh beberapa literatur, yaitu Service Profit Chain (SPC), Structure Conduct Outcomes (SCO) dan Balanced Scorecard (BSC). Namun demikian model pengukuran kinerja yang sering dijadikan acuan untuk pengembangan kerangka pengukuran performansi adalah Balanced Scorecard yang diusulkan oleh Kaplan dan Norton pada tahun 1997 (Kim, et al., 2007). Kelebihan utama dari model Balanced Scorecard adalah mendidik manajemen dan organisasi untuk memandang perusahaan dari empat perspektif yaitu keuangan (financial), pelanggan (customer), proses bisnis internal (internal business process), dan pembelajaran dan pertumbuhan (learning and growth), yang menghubungkan pengendalian operasional jangka pendek ke dalam visi dan strategi bisnis jangka panjang.

CRM Scorecard merupakan sebuah framework pengukuran kinerja yang dikembangkan oleh Hyung-Su Kim danYoung-Gul Kim (2007) yang mampu mendiagnosis dan menilai praktik CRM sebuah perusahaan. Kerangka kerja tersebut menggunakan empat perspektif yang dijadikan sebagai acuan untuk mendiagnosis faktor-faktor keberhasilan atau kegagalan praktik CRM yaitu infrastruktur, proses, pelanggan dan performa organisasi. Model pengukuran kinerja CRM Scorecard secara detail disampaikan pada Tabel 1 di bawah ini dan telah dicantumkan instrumen-instrumen pengukurannya. 


\begin{tabular}{|c|c|c|c|}
\hline \multirow[t]{2}{*}{ Perspective } & \multirow{2}{*}{$\begin{array}{c}\text { Diagnostic } \\
\text { Factors }\end{array}$} & \multicolumn{2}{|r|}{ Instruments } \\
\hline & & Subjective & Objective \\
\hline \multirow{3}{*}{$\begin{array}{l}\text { Organizational } \\
\text { Performance }\end{array}$} & Shareholder value & & SHV \\
\hline & Profitability & $\begin{array}{l}\text { Perceptual } \\
\text { performance }\end{array}$ & $\begin{array}{l}\text { ROA, ROI, Net sale (\$), Net } \\
\text { sales/employee }\end{array}$ \\
\hline & Customer Equity & & $\begin{array}{l}\text { Customer equity, CLV, } \\
\text { Profit/customer }\end{array}$ \\
\hline \multirow{3}{*}{ Customer } & Customer Loyalty & Perceived loyalty & RFM \\
\hline & $\begin{array}{l}\text { Customer } \\
\text { Satisfaction }\end{array}$ & $\begin{array}{l}\text { Perceived customer } \\
\text { satisfaction }\end{array}$ & Satisfied customer ratio (\%) \\
\hline & Customer Value & $\begin{array}{l}\text { Perceived value, } \\
\text { brand equity, } \\
\text { relationship }\end{array}$ & Customer complaints (\#) \\
\hline \multirow[t]{3}{*}{ Process } & $\begin{array}{l}\text { Customer } \\
\text { Acquisition }\end{array}$ & $\begin{array}{l}\text { Readiness for } \\
\text { acquisition process }\end{array}$ & $\begin{array}{l}\text { Leads per channel, acquisition (\#), } \\
\text { visits of web (\#), win-back (\%), } \\
\text { profitability of new customer, } \\
\text { response rate, sales success rate } \\
\text { (hit ratio), customer contact rate }\end{array}$ \\
\hline & Customer Retention & $\begin{array}{l}\text { Readiness for } \\
\text { retention process }\end{array}$ & $\begin{array}{l}\text { Response time (wait time), } \\
\text { complaints resolved on } 1^{\text {st }} \text { call } \\
(\%) \text {, retention rate }(\%) \text {, delivery } \\
\text { time, customer churn rate, reject } \\
\text { rate by delivery, trouble tickets } \\
\text { cleared }\end{array}$ \\
\hline & $\begin{array}{l}\text { Customer } \\
\text { Expansion }\end{array}$ & $\begin{array}{l}\text { Readiness for } \\
\text { expansion process }\end{array}$ & $\begin{array}{l}\text { Share of wallet (\%), core } \\
\text { customer ratio (\%), cross/up-sell } \\
\text { rate, value per order }\end{array}$ \\
\hline
\end{tabular}

\begin{tabular}{|c|c|c|c|c|}
\hline \multirow{2}{*}{\multicolumn{2}{|c|}{ Perspective }} & \multirow{2}{*}{$\begin{array}{c}\text { Diagnostic } \\
\text { Factors }\end{array}$} & \multicolumn{2}{|r|}{ Instruments } \\
\hline & & & Subjective & Objective \\
\hline \multirow[t]{10}{*}{$\begin{array}{l}\text { Infrastr } \\
\text { ucture }\end{array}$} & IT & CRM Technology & $\begin{array}{l}\text { Sys/info quality, } \\
\text { system usability, } \\
\text { user SAT, Ind. } \\
\text { influence }\end{array}$ & $\begin{array}{l}\text { Technological capacity for } 3 \text { types } \\
\text { of customer Info. (\#), customer } \\
\text { info. accuracy (\%), customer info. } \\
\text { inte gration (\%), system stability }\end{array}$ \\
\hline & \multirow[t]{3}{*}{$\begin{array}{l}\text { Human } \\
\text { Capital }\end{array}$} & Employee Behavior & $\begin{array}{l}\text { Customer oriented } \\
\text { attitude }\end{array}$ & $\begin{array}{l}\text { Human capital readiness (\%), time } \\
\text { per job, calls handled per call } \\
\text { center staff (sales rep coverage) }\end{array}$ \\
\hline & & $\begin{array}{l}\text { Employee } \\
\text { Satisfaction }\end{array}$ & $\begin{array}{l}3 \text { justices for } \\
\text { Employee } \\
\text { satisfaction }\end{array}$ & Key employee turnover \\
\hline & & $\begin{array}{l}\text { Management } \\
\text { Attitude }\end{array}$ & $\begin{array}{l}\text { Perception \& } \\
\text { support for CRM }\end{array}$ & \\
\hline & \multirow{3}{*}{$\begin{array}{l}\text { Strategic } \\
\text { Alignment }\end{array}$} & Training & Training procedure & Training days/employee \\
\hline & & Reward System & $\begin{array}{l}\text { Appropriateness of } \\
\text { reward system }\end{array}$ & \\
\hline & & $\begin{array}{l}\text { Organizational } \\
\text { Structure }\end{array}$ & $\begin{array}{l}\text { Organizational } \\
\text { flexibility }\end{array}$ & Improvement in diversity profile \\
\hline & \multirow[t]{3}{*}{ Culture } & Partnership & Coordinating effort & Vendor diversity \\
\hline & & Market Orientation & Market orientation & $\begin{array}{l}\text { Frequency of customer survey, } \\
\text { customer knowledge creation (\#) }\end{array}$ \\
\hline & & Explicit Goal & $\begin{array}{l}\text { Explicitness of } \\
\text { Goal }\end{array}$ & \\
\hline
\end{tabular}

Gambar 1 Model Pengukuran Kinerja CRM

Sumber: Hyung-Su Kim danYoung-Gul Kim (2007) 


\section{METODE}

Metode penelitian ini bersifat deskritif analitis, yaitu suatu penelitian yang bermaksud untuk memberikan gambaran tentang suatu kejadian atau permasalahan tertentu, di mana sudah ada informasi mengenai gejala tersebut. Namun informasi mengenai gejala tersebut belum memadai, sehingga untuk dapat menjelaskan lebih rinci dan memberikan solusi penyelesaian masalah tersebut, maka penelitian ini akan memberikan kajian sesuai dukungan teori yang terkait dengan permasalahan tersebut. Perolehan data dilakukan melalui metode riset kepustakaan (Library Research) dan riset data sekunder yang bersumber dari melalui internet atau website resmi dari Bank Indonesia dan website resmi lainnya yaitu www.aspective.com serta hasil riset yang dilakukan oleh MarkPlus Insight tentang persaingan perbankan.

Metode analisis yang digunakan dalam penelitian ini menggunakan pendekatan analisis kualitatif terhadap hasil penelitian yang telah dilakukan oleh MarkPlus Insight. Sumber informasi lainnya yaitu Bank Indonesia dan www.aspective.com. Peneliti melakukan pendalaman analisis secara kualitatif yang didukung oleh kajian teori yang telah ada tentang konsep CRM dan pengukurannya.

\section{HASIL DAN PEMBAHASAN}

\section{Karakteristik Pelayanan dalam Industri Perbankan}

Industri perbankan merupakan salah satu industri yang harus mengutamakan pelayanan dalam keamanan, kenyamanan, kemudahan, kecepatan dan ketepatan waktu. Untuk mendukung persyaratan tersebut industri ini memerlukan perangkat teknologi tinggi, sehingga diperlukan dana cukup besar bagi pemain baru. Selain itu, industri perbankan harus memenuhi skala ekonomis melalui peningkatan kemampuan mendapatkan dan pengelolaan dana pihak ketiga sehingga dapat menghasil keuntungan yang memadai dan berkesinambungan serta harus terus dapat menekan biaya operasi melalui pemanfaatan IT serta senantiasa meningkatkan kualitas pelayanan.

Modal utama yang digunakan untuk operasional di industri perbankan adalah modal yang bersumber dari dana masyarakat, sehingga industri perbankan sangat rentan terhadap perilaku dan isu nasabah. Nasabah dapat dengan cepat menarik dana jika terdapat kondisi yang kebutuhan dana mendesak dan/atau berkurangnya tingkat kepercayaan terhadap industri perbankan. Untuk itu, perbankan merupakan salah satu industri yang menekankan tingkat kepercayaan karena penggunaan dana nasabah.

Seiring dengan cepatnya perubahan perilaku masyarakat dan teknologi informasi dan telekomunikasi yang berkembang, industri perbankan dituntut untuk mengikuti perkembangan perilaku masyarakat yang membutuhkan pelayanan cepat, nyaman, dan aman dalam kebutuhan transaksi perbankan. Untuk itu perbankan yang memiliki jaringan distribusi Automatice Teller Machine (ATM) yang luas dan didukung pula layanan internet banking serta mobile banking, merupakan perbankan yang menjadi idaman masyarakat. Bank-bank papan atas yang menguasai pasar 60\% yaitu Bank Mandiri, BRI, BCA, BNI, CIMB Niaga, Danamon, PANIN, Permata, BII, dan BTN, merupakan bank-bank dengan kemampuan investasi teknologi informasi terbesar (Bank Indonesia, 2011).

Demikian pula bila dilihat dari pertumbuhan Return on Asset (ROA), dibandingkan dengan negara lain di dunia. Perbankan Indonesia memiliki pertumbuhan ROA tertinggi, yaitu mencapai 3.1\% sementara negara-negara lainnya seperti Amerika mencapai 1.05\%, Eropa 0.14\%, dan Asia Pasifik 
1.15\%. Di Indonesia, terdapat empat bank papan atas yang memiliki ROA tertinggi, yaitu BRI (4.87\%), Mandiri (3.45\%), BCA (3.40\%), dan BNI (2.80\%). Indikasi ini memberikan informasi bahwa industri perbankan Indonesia memiliki daya tarik yang tinggi dibandingkan dengan negara-negara lain di dunia.

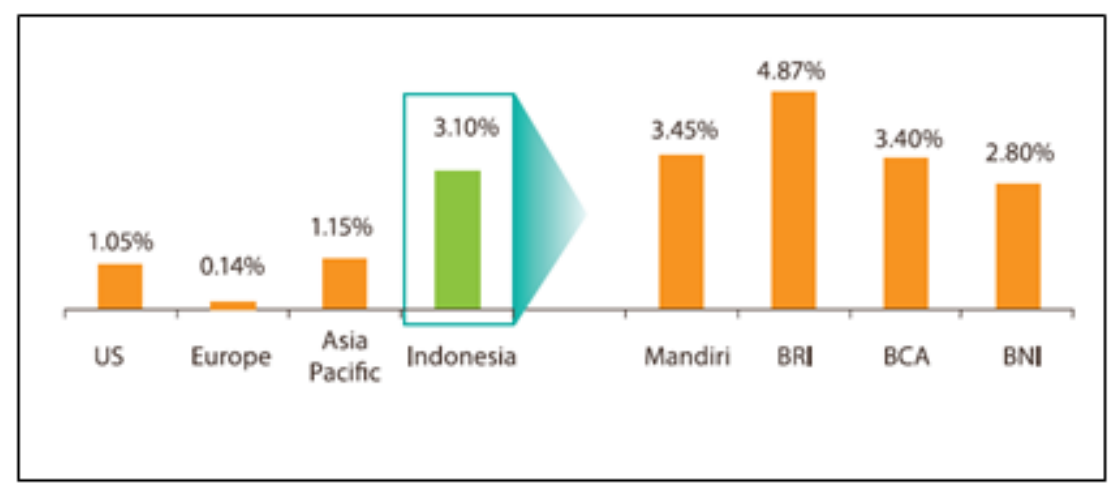

Gambar 2 Return on Asset Perbankan Dunia dan Indonesia per September 2012 (Sumber: Kertajaya, 2014)

Tingginya daya tarik industri perbankan tersebut, mengindikasikan pula adanya perang dalam kualitas pelayanan yang berbasiskan pada teknologi informasi. Sebagian besar bank-bank papan atas terus berlomba untuk meraih nasabah potensial melalui strategi pelayanan pelanggan. Berbagai kemudahan dan keuntungan yang ditawarkan bank-bank papan guna mendapatkan nasabah potensial. Perbankan yang unggul dalam persaingan tersebut memiliki kemampuan dalam mengelola nasabah melalui teknologi informasi.

\section{CRM sebagai Solusi Membangun Hubungan Baik Pelanggan}

Hasil riset yang dilakukan oleh Kertajaya, et al (2014) tentang Banking Competition in 2013, terdapat korelasi antara indeks program loyalitas yang dilakukan perbankan dengan kenaikan indeks loyalitas nasabah. Hal ini mengindikasikan bahwa perbankan yang peduli membangun loyalitas pelanggan melalui program-program CRM, memiliki indikasi peningkatan loyalitas pelanggan. Loyalitas pelanggan tidak bertahan lama, oleh sebab itu, setiap perbankan selalu memperbaharui program loyalitas untuk menarik nasabah lebih banyak. Hal ini membuat perbankan dituntut untuk terus kreatif dan inovatif dalam mengembangkan program CRM untuk tetap mempertahankan nasabahnya. Artinya, CRM tidak bisa diterapkan secara konvensional tanpa dukungan teknologi informasi.

Penerapan CRM berbasiskan pada teknologi informasi pada industri perbankan menjadi sebuah keharusan. Hal ini seperti yang telah disampaikan di atas bahwa karakteristik industri perbankan sangat rentan dengan tingkat kepercayaan masyarakat dalam menempatkan dananya di sebuah bank. Pentingnya teknologi informasi dalam perbankan karena tuntutan masyarakat dalam pelayanan perbankan sangat tinggi, yaitu keamanan, kenyamanan, kemudahan, kecepatan dan ketepatan waktu. Tuntutan pelayanan ini hanya dapat dipenuhi dengan penerapan teknologi informasi di perbankan.

Perbankan akan kurang diminati masyarakat atau bahkan tidak mendapatkan kepercayaan masyarakat bila tidak menerapkan teknologi informasi. Walaupun diakui bahwa investasi teknologi informasi demikian tinggi dan perkembangan teknologi informasi pun demikian cepatnya sehingga biaya investasi menjadi terus meningkat. Namun demikian, besarnya investasi tersebut akan tertutupi 
oleh loyalitas pelanggan karena kebutuhan pelanggan dalam pelayanan, keamanan, kenyamanan, kemudahan, kecepatan dan ketepatan waktu dapat dipenuhi.

Mengutip pernyataan yang disampaikan oleh O’Brien (2002:130), bahwa CRM yang berbasiskan pada teknologi informasi dimaksudkan untuk menciptakan cross-functional enterprise system yang mengintegrasikan dan mengotomatisasi proses layanan pelanggan dalam bidang penjualan, pemasaran, dan layanan produk/jasa berkaitan dengan perusahaan. Dengan demikian sebuah sistem CRM juga akan menciptakan IT framework yang menghubungkan semua proses dengan bisnis operasional perusahaan yang terkait dengan kebutuhan pelayanan kepada pelanggan. Artinya penerapan CRM akan menjadi tidak maksimal bila dijalankan tanpa dukungan teknologi informasi. Inilah pentingnya teknologi informasi dalam industri perbankan guna pelayanan kepada pelanggan dan membangun hubungan baik kepada pelanggan, sehingga pada akhirnya perusahaan akan mendapatkan loyalitas pelanggan.

\section{Model Pengukuran Kinerja CRM}

Pengukuran kinerja CRM perlu dilakukan karena aplikasi CRM akan menjadi efektif bila didukung pula dengan teknologi informasi. Di sisi lain, teknologi informasi merupakan perangkat dengan nilai investasi yang sangat besar. Sehingga pengelolaan pelanggan yang didukung dengan teknologi informasi akan menjadi efisien dan efektif apabila kinerjanya terukur. Baik itu terukur kinerjanya di sisi operasional perusahaan maupun di sisi pelanggan. Selain itu, membangun hubungan baik merupakan kerangka strategi jangka panjang sehingga perlu pengukuran setiap tindakan-tindakan dan strategi jangka pendek yang mengarah kepada kinerja CRM.

Mengacu pendapat yang dikemukakan oleh Brewton (2009) bahwa penerapan CRM merupakan kerangka kerja strategi jangka panjang perusahaan. Berdasarkan CRM perusahaan dapat mengukur setiap strategi jangka pendek untuk mendapatkan manfaat yang dirasakan perusahaan dan pelanggan. Sehingga, antara perusahaan dan pelanggan dapat saling mengukur manfaat atas kerja sama pelayanan perusahaan.

Model pengukuran kinerja CRM yang dikembangkan oleh Hyung-Su Kim danYoung-Gul Kim (2007) yaitu CRM Scorecard merupakan salah satu model pengukuran yang paling sesuai untuk mengukur keberhasilan penerapan CRM di perbankan. Alasan ini karena CRM Scorecard dikembangkan dari model pengukuran Balanced Scorecard (BSC) yang dikembangkan oleh Kaplan dan Norton (1993). BSC merupakan pengukuran kinerja organisasi yang sangat komprehensif. Sejalan dengan konsep BSC, Hyung-Su Kim danYoung-Gul Kim (2007) mengembangkan CRM Scorecard dengan menekankan kepada dua sisi penting yaitu sisi eksternal untuk pelanggan yang diukur oleh Customer Perspective yang meliputi aspek-aspek customer loyaty, customer satisfaction, dan customer value. Sedangkan untuk sisi internal perusahaan diukur oleh tiga perspektif yaitu Organizational Performance, Process, dan Infrastructure. Pada perspektif infrastruktur memiliki ukuran yang cukup lengkap yaitu Information Technology, Human Capital, Strategic Aligment, dan Culture.

Untuk menjawab permasalahan inti pada penelitian ini, yaitu perlunya pengukuran CRM pada sisi investasi teknologi informasi, Hyung-Su Kim danYoung-Gul Kim (2007) telah menjawab permasalahan tersebut dengan mengembangkan sub perspektif IT Infrastrucure pada Infrastrucure Perspective. Adapun diagnostic factors yang diukur CRM Technology dengan ukuran objektif meliputi technology capacity for three types of customer info, customer info accuracy, customer info integration, dan system stability. Artinya model CRM Scorecard merupakan model yang sesuai bagi industry perbankan untuk mengukur kinerja CRM secara komprehensif dan terintegratif.

Bagi perbankan, pembangunan CRM berbasiskan teknologi informasi dapat diukur melalui Return on Investment (ROI) investasi teknologi informasi dengan keuntungan yang didapat secara jangka panjang. Dengan demikian, CRM akan membantu perusahaan dalam mengukur seberapa besar 
investasi yang ditanamkan dan seberapa besar keuntungan yang diperoleh perusahaan dan nasabah atas jalinan hubungan baik yang saling menguntungkan tersebut. Artinya investasi teknologi informasi tidak lagi dipandang sebagai investasi yang mahal (cost center) namun telah berubah menjadi profit center bagi perusahaan.

\section{SIMPULAN}

Industri perbankan merupakan salah satu industri dengan karaktersitik industri yang sangat rentan dengan tingkat kepercayaan nasabah. Mereka dapat dengan cepat menarik dana jika terdapat kondisi yang mendesak terhadap kebutuhan dana dan/atau tingkat kepercayaan nasabah yang menurun terhadap industri perbankan. Selain itu, persaingan yang tinggi dalam industri perbankan menuntut industri perbankan untuk cerdas dalam mengelola hubungan baik kepada pelanggan melalui CRM. Namun disisi lain, aplikasi CRM akan menjadi efektif bila didukung dengan teknologi informasi. Investasi teknologi informasi bukanlah hal yang kecil, sejalan dengan semakin tinggi teknologi informasi semakin besar pula nilai investasinya.

Penelitian ini telah menghasilkan model penerapan CRM dalam industri perbankan yang efisien dan efektif melalui penerapan teknologi informasi. Penerapan CRM yang berbasiskan teknologi informasi dengan investasi yang besar akan menjadi bernilai bagi perusahaan dan nasabah bila diikuti pula dengan pengukuran kinerja secara benar. CRM Scorecard merupakan salah satu model pendekatan yang tepat dalam mengukur kinerja CRM yang berbasiskan teknologi informasi. Melalui pendekatan CRM Scorecard, investasi teknologi informasi dalam CRM tidak lagi dipandang sebagai cost center namun menjadi profit center karena perusahan dapat mengelola pelanggan secara efisien dan efektif guna meningkatkan nilai perusahaan di masa mendatang.

\section{DAFTAR PUSTAKA}

Bank Indonesia (2011), Laporan Perkembangan Pelaksanaan Tugas dan Wewenang Bank Indonesia Triwulan IV Tahun 2011, Jakarta: Bank Indonesia

Brewton, J. (2009). Want to Maximize YourCRM Performance? Measure It! Diakses dari URL:http://www.opentec.com.mx/pdf/Want_to_Maximize_your_CRM_Performance_Measur e_it.pdf

Cannon, J. P., Perreault, William, D., McCarthy, E., Jerome, 2008, Basic Marketing: A GlobalManagerial Approach., New York: McGraw-Hill.

Costanzo, C. (2003), Moving Focus of CRMEfforts From Software to Employees. AmericanBanker, 168(116), 8

Greenberg, I. (2001). Special Report: E-Businessin Asia: Customer driven. Asiaweek, 1

Gupta, S., Donald R., Lehman, AmesStuart, J. (2002) Valuing Customers, Columbia Business School.

Kaplan, S, Robert., Norton, David, P. (1993). Putting Balanced Scorecard to Work. Harvard Business Review, 2-16 
Kertajaya, Hermawan, et al., (2014) Banking Competitionin 2013: in the Time of Regulatory Transition. Hasil Riset MarkPlus Consulting.

Kim, Hyung-Su., Kim, Young-Gul. (2007). A Study onDeveloping CRM Scorecard. Proceedings of the $40^{\text {th }}$ Hawaii International Conference on System Sciences.

O’Brien, J. A., (2002). Customer RelationshipManagement, Management InformationSystems: Managing Information Technology inthe E-Business Enterprise. New York: McGraw-Hill Higher Education.

Whitaker, T. (2005). Streamline customer contact. Landscape Management, 44(4), 50

Winer. (2001). Customer Relationship Management. A Framework, Research Directions, and the Future. Lecture conducted at Haas School of Business, University of California, Barkeley. 